\title{
Yaşlı hasta popülasyonunda perkütan endoskopik gastrostomi
}

\author{
Percutaneous endoscopic gastrostomy in older patient population
}

Diğdem ÖZER ETIK, Nuretdin SUNA, Serkan ÖCAL, Haldun SELÇUK

Başkent Üniversitesi Tip Fakültesi, Ankara Hastanesi, Gastroenteroloji Bilim Dall, Ankara

Giriş ve Amaç: Perkütanöz endoskopik gastrostomi, sıkllkla beslenme problemi olan ve uzun süreli tüple beslenme ihtiyacı olan bireylerde kullanılmaktadır. Bu çalışmanın amacı, öncelikle, kliniğimizde yıllar içinde değişen perkütanöz endoskopik gastrostomi kullanımı ve hasta özelliklerini saptamaktı. Ikincil amaç olarak da, orta yaş ve yaşlı hasta popülasyonunda perkütanöz endoskopik gastrostomi endikasyonlarını, komplikasyonlarını ve perkütanöz endoskopik gastrostomi uygulaması sonrası sağ kalımı karşılaştırmaktı.

Gerec ve Yöntem: Mayıs-2011 ve Haziran-2015 tarihleri arası merkezimizde perkütanöz endoskopik gastrostomi uygulanan hastaların verileri retrospektif olarak değerlendirildi. Demografik ve klinik özellikler kaydedildikten sonra, komplikasyonlar ve sağ kalım değerlendirildi. Bütün bu sonuçlar, orta yas ve yaşlı hasta grubunda karșılaștırıldı. Bulgular: Çalışmada 298 hastanın bilgileri değerlendirildi. 156 kadın ve 142 erkek hastanın ortanca yaşı 82 idi. En sık perkütanöz endoskopik gastrostomi endikasyonu sereberovasküler hastalık idi. Yıllar içinde hasta popülasyonumuzun daha yaşlı bir hasta popülasyonu yönünde değistiğini saptadık. Orta yaş ve yaşlı hasta gruplarında klinik sonuçlar ve perkütanöz endoskopik gastrostomi komplikasyonlar açısından benzer sonuçlar gözlenirken, sadece hastanede kalma süresi yașlı grupta daha uzundu. 3 aylık ve 1 yıllık sağ kalım karşılaştırıldığında iki grup açısından fark yoktu. Sonuç: Dünya ve ülkemiz nüfusu yaşlanırken, özellikle geriatrik hastalarda, perkütanöz endoskopik gastrostomi güvenli bir yöntem olup mortaliteyi arttırmamaktadır.

Anahtar kelimeler: Perkütan endoskopik gastrostomi, serebrovasküler olay, yaşlanma, sağ kalım
Background and Aims: Percutaneous endoscopic gastrostomy is commonly used in patients with nutrition problems who require long-term tube feeding. The first aim of this study was to investigate the change in percutaneous endoscopic gastrostomy utilization and patient characteristics over time in our clinic. Our second aim was to compare older and middle-aged patients in terms of indications for percutaneous endoscopic gastrostomy, complications, and survival following percutaneous endoscopic gastrostomy insertion. Materials and Methods: We conducted a retrospective study in which the data on patients who underwent percutaneous endoscopic gastrostomy placement between May 2011 and June 2015 were analyzed. After demographic and clinical variables were collected, complications and survival were assessed. All outcomes of older and middle-aged patients were compared. Results: Data on 298 patients were evaluated. There were 156 women and 142 men, with a median age of 82 years. The prevailing indication for percutaneous endoscopic gastrostomy insertion was cerebrovascular disorders. We noticed that the mean age of our patient population had increased over the years. Clinical outcomes and complications, except length of stay in hospital, were similar in the two groups. There was no difference in the 3-month-and 1-year survival rates between older and middle-aged patients. Conclusion: As the national and global populations age, percutaneous endoscopic gastrostomy is a safe procedure and is not associated with increased mortality, especially in geriatric patients.

Key words: Percutaneous endoscopic gastrostomy, cerebrovascular disorders, aging, survival

invaziv olması, düşük oranda komplikasyon ve morbiditeye yol açması, uzun ömürlü ve güvenli bir beslenme yolu sağlaması gibi avantajları taşımaktadır (3-5). Sıklıkla serebrovasküler hastalık, amiyotrofik lateral skleroz, demans gibi nörolojik hastalıklar ve baş-boyun kanserleri gibi onkolojik hastalıklarda benimsenmektedir (6).

Son yıllarda kliniğimize PEG uygulaması talebi ile başvuranların sayısının arttığını gözlemlemekteyiz. Merkezimizdeki diğer kliniklerin ve yoğun bakım ünitesinin gastroenteroloji ile ortak yaklaşımı, hasta yakınlarının artan farkındalığı, bakımevlerinin PEG bakımı ve PEG'den beslenme deneyimlerinin artması PEG işlemi öncesi ve sonrası süreci kolaylaştırmaktadır. Bu retrospektif çalışma ile kliniğimizde son 5 yılda uygulanan PEG endikasyonlarını, hasta özelliklerini, işlem 
komplikasyonlarını, hasta sağ kalım sürelerini yıllara göre değerlendirmeyi amaçladık. Ayrıca 79 yaş altı hastaları orta yaş grubu, 80 yaş ve üstü hastaları yaşlı hasta grubu olarak ayırarak PEG uygulamalarımızın bu iki grupta karşılaştırılmasını hedefledik.

\section{GEREC ve YÖNTEM}

\section{Hasta Bilgilerinin Toplanması}

Başkent Üniversitesi Ankara Hastanesi 2011 yll Mayıs ayından bu yana Nucleus yazılım sistemini kullanmaktadır. Buna istinaden sistemde 'perkütan endoskopik gastrostomi' işlem kodu ile 2011- Haziran ile 2016-Haziran tarihleri arası için tarama yaparak hastanemiz Gastroenteroloji Kliniği tarafından uygulanan ve teknik olarak tamamlanan işlemlerin listesi çıkarıldı.

Her hastanın demografik bilgileri yanında, mevcut hastalıkları, PEG endikasyonu, işlem sonrası hastanede yatış süresi, kayitlara geçen PEG işlemi sonrası komplikasyonu kaydedildi. Hastaların mevcut hastalıkları; hipertansiyon, diabetes mellitus, koroner arter hastalığı, kalp yetmezliği, kronik obstrüktif akciğer hastalığı, pnömoni, akut/kronik böbrek yetmezliği ve kronik karaciğer hastalığı olarak sınıflandırılarak kaydedildi. PEG endikasyonlarından nörolojik hastalıklar alt gruplara ayrıldı. Hemorajik veya iskemik sebebe bağlı inme, demans (diffüz serebral atrofi, Alzheimer, vasküler demans), demyelinizan hastalık [multiple skleroz (MS), akut dissemine ensefalomiyopati (ADEM)], progresif multifokal lökoensefalopati (PML), motor nöron hastalığı (amiyotrofik lateral skleroz-ALS), hareket bozukluğu (Parkinson hastalığı), hipoksik serebral hasar başlıkları alında gruplandırıldı. Intrakranial kanama, Wilson hastalığının nörolojik tutulumu, ensefalit, hidrosefali, elektrik çarpması veya trafik kazasına bağlı nörolojik hasarlar sınıflandırma dışında "diğer" başlığı altında toplandı. PEG komplikasyonları majör ve minör komplikasyonlar olarak sinıflandırıldı. Majör komplikasyonlar kanama, internal organ hasarı, tampon gömülmesi, gastro-kolo-kutanöz fistül, ileus ve nekrotizan fasiitis olarak kabul edildi. Stoma yerinden sızıntı, enfeksiyon, granülom, herni, tüp dislokasyonu, tüp tıkanması ise minör komplikasyon olarak değerlendirildi.

Hastaların hastanede kalma ve takip süreleri gün olarak kaydedildi. Hastaların sağ kalımlarına ilişkin bilgi telefonla aranarak kendi veya yakınlarından öğrenildi. Telefon ile ulaşlamayan hastalarda hastane kayıt sistemlerinin doğrudan bağlantılı olduğu Merkezi Nüfus Idaresi Sistemi kullanıldı. Bu sistemden vefat eden hastalarımızın vefat tarihleri kaydedildi.

Hastaların tekrarlayan PEG gereksinimi bilgisi yine Başkent Unniversitesi Ankara Hastanesi kaylt sisteminden elde edildi. Hasta veya hasta yakını telefon görüşmesinde de tekrarlayan
PEG uygulaması sorgulandı, eğer kliniğimiz dışında başka bir sağlık merkezinde yeniden PEG uygulanmış ise buna ait bilgiler çalışma dışı bırakıldı, sadece hastanemizde uygulanan ilk PEG uygulamasının bilgileri kullanıldı. Tüm veriler 2011'den 2016'ya kadar yıllara göre gruplandırılarak karşılaştırıldı. Ayrıca hastalar yaşlarına göre orta yaş (79 yaş ve altı) ile yaşlı (80 yaş ve üzeri olarak) gruplandırılarak değerlendirildi.

\section{İşlem Öncesi Hazırlık}

Kliniğimizde her PEG işlemi öncesi hastaların PEG endikasyonu, talep eden hekim ile konsülte edilerek konulmaktadır. Ardından hasta ve/veya hasta yakınına bilgi verilerek işlem onamı alınır. Sonrasinda hasta anestezi hekimi tarafindan görülerek işlem risk değerlendirmesi yapılır ve zamanlaması belirlenir. Hastanın kullanmakta olduğu antiagregan ve antikoagülan ilaçlar güvenli işlem için gereken optimum süre kesilir ve/veya ilaç kullanım endikasyonuna göre düşük molekül ağırlıklı heparin kullanımına geçilir. Işlem günü tüm hastaların tam kan sayımı ve koagülasyon parametreleri ölçülür. İşlemden 6 saat öncesinde seftriakson 2 gr parenteral olarak uygulanmaktadır.

Düzeltilmemiş koagülasyon bozukluğu, hemodinamik instabilite, peritonit, sepsis, giriş alanında enfeksiyon varlığı, peritonitis karsinomatoza, total gastrektomi hikayesi ve gastrik varisleri bulunanlara PEG uygulanmamaktadır.

\section{PEG Uygulama Tekniği}

PEG işlemi, endoskopi ekibi tarafından Gauderer ve arkadaşları tarafından tanımlanan "çekme" tekniği kullanılarak uygulanmaktadır (7). Her işlem, anestezi ekibi tarafından uygulanan sedasyon altında yapılmaktadır. Merkezimizde son 5 yllda, işlemin perkütan kısmında cilt insizyonu yerine sadece iğne ponksiyon alanından beslenme tüpü yerleştirilmektedir. Işlemden 6 saat sonra, hastanemiz nutrisyon ekibi işbirliğinde PEG kateteri üzerinden beslenme başlanmaktadır.

\section{İstatistiksel Analiz}

Değişkenlerin analizinde SPSS 22.0 (IBM Corparation, Armonk, New York, United States) programı kullanıldı. Verilerin normal dağılıma uygunluğu Shapiro-Wilk testi ile varyans homojenliği Levene testi ile değerlendirildi. Ikiden fazla grubun nicel verilere göre bir biriyle karşılaştırılmasında Wallis H Testi Monte Carlo sonuçlarıly birlikte kullanılırken Post Hoc analizler için Dunn's Testi kullanıldı. Kategorik değişkenlerin birbiri ile karşılaştırılmasında ise Pearson Chi-Square testi Monte Carlo Simülasyon tekniği ile test edildi ve sütun oranları birbiri ile karşılaştırllıp Bonferroni düzeltmeli p değeri sonuçlarına göre ifade edildi. Faktörlerin mortalite ile yaşam sürelerine etkilerini incelemek için Kaplan-Meier (product limit method) analizi kullanıldı. Nicel değişkenler tablolarda medyan range (maksimum-minimum), kategorik 
değişkenler ise n (\%) olarak gösterildi. Değişkenler \%95 güven düzeyinde incelenmiş olup p değeri 0,05’ten küçük ise anlamlı kabul edildi.

\section{BULGULAR}

Çalışmaya 298 hasta dahil edildi. Hastaların \%52,3’ü kadın, $\% 47,7$ 'si erkekti. Hastaların ortanca yaşı 82 yldı (minimum: 18 yll, maksimum: 106 yll). 2011 yllından başlayarak PEG uygulanan hasta sayısı 2015'e kadar yllara göre sirasiyla 50, 59, 61, 62, 66 idi ( $\mathrm{p}=0,013) .2011$ yllinda kadın hasta sayısı 29 iken 2015 yllında bu sayı 36'ya artmakla birlikte istatistiksel fark izlenmedi $(\mathrm{p}=0,885)$. Hastaların ortanca yaş değerleri yıllara göre bakıldığında 2011 yılında ortanca yaş 79,5 yl (minimum: 18 yll, maksimum: 102 yll) iken, 2015 yllında ortanca yaş 86 yıldı (minimum: 18 yll, maksimum: 106 yll). Hastalar orta yaş ve yaşlı olarak gruplandırıldığında; birinci grupta 115 hasta, ikinci grupta 183 hasta bulunmakta idi. Birinci grubun \%42'si kadın iken, ikinci grubun kadın hasta oranı \%58,5 idi $(\mathrm{p}=0,009)$. Hastaların mevcut hastalıklarına bakıldığında \%30,5 oranı ile hipertansiyon en sık görülen ek hastalı olup bunu diabetes mellitus, sonrasında da kronik obstrüktif akciğer hastalığı takip etmekteydi. Eşlik eden hastalık açısından orta yaş ve yaşlı grup arasında istatistiksel olarak farklılık saptanmadı.

Hastaların PEG endikasyonu Tablo l'de özetlenmiş olup serebrovasküler olay (SVO) her yll için en sik sebepti, yllar içinde de en fazla artan endikasyondu $(p=0,001)$. PEG endikasyonlarında 80 yaş ve üzeri grupta SVO ve demans, 79 yaş ve alt grupta hipoksik ensefalopati ve maligniteler daha fazla görülmekte idi ( $p>0,001) .18$ hastada PEG gerektiren primer malignite bulunurken, 6 hastada PEG endikasyonu gösteren nörolojik hastalığa eşlik eden malignite saptandı. Maligniteler içinde akciğer karsinomu ilk sırada olup, bunu sırasıyla beyin tümörleri, özofagus karsinomu ve baş-boyun karsinomları takip etmekteydi. Hastalar orta yaş ve yaşlı olarak gruplandırıldığında; PEG endikasyonları açısından yaşlı grupta daha fazla demans görülürken, orta yaş grubunda daha fazla hipoksik ensefalopati ve malignite görülmekte idi $(\mathrm{p}=0,05)$.

Hastaların PEG uygulaması sonrası hastanede kalma süreleri karşılaştırıldığında, orta yaş grubunda bu süre ortanca \pm çeyrekler arası aralık (IQR) olarak $7 \pm 15$ gün iken, yaşlı grupta

Tablo 1. Hastaların demografik ve klinik özellikleri, perkütan endoskopik gastrostomi işlemi endikasyon ve komplikasyonları ile sağ kalım oranlarının yaşa göre karşılaştırması

79 Yas ve Altı $(\mathrm{n}=115)$

Cinsiyet (Kadın/Erkek)
PEG endikasyonları (\%)

SVO

Demans

Hipoksik ensefalopati

Parkinson

Malignite

Diğer

Ek hastalık (\%)

Diabetes Mellitus

$49 / 66$

42,6

14,8

$13,1^{\mathrm{b}}$

5,2

$11,3^{\mathrm{b}}$

$13,0^{\mathrm{b}}$

7,7

23

Kalp yetmezliğ

Kronik böbrek hastalığı

PEG komplikasyonları (\%)

Hastanede kalma süresi (gün)

Sağ kalım (\%)

3. ay

1. yıl

13

2,6

$7 \pm 15$

70,9

53,7
80 Yas ve Üzeri $(\mathrm{n}=183)$

107/76

$11 \pm 28$
43,2

$42,1^{\text {a }}$

1,6

6,0

2,6

4,4

8

1

23,4

14,2

2,7

18,1

1

0,003 *

65

0,110

P

0,009 *

$<0,001$

46

PEG: Perkütan endoskopik gastrostomi, SVO: Serebrovasküler olay.

${ }^{*} \mathrm{P}<0,05$, istatistiksel olarak anlamlıdır.

a: 80 yaş ve üzeri grup için anlamlı sonuç

b: 79 yaş ve altı için anlamlı sonuç 
$11 \pm 28$ gün idi $(\mathrm{p}=0,003)$. Yeniden PEG uygulama ihtiyacı $46(\% 15,4)$ hastada 2 kez, 18 (\%6) hastada 3 kez, yalnızca bir hastada ise 4 kez olmuştu. En sık PEG yenileme endikasyonu tüp deformasyonuydu. 4 kez PEG takılan hastanın ise tüpü kendi çekmesi sebebiyle uygulama tekrar edildi. Yeniden PEG uygulama endikasyonu ve sıklı̆̆ yaş gruplarına göre farklılık göstermemekteydi $(\mathrm{p}=1)$.

En sik komplikasyon peristomal kanama $(\% 3,4)$ ve peristomal sızıntı $(\% 3,4)$ idi. Tekrarlayan PEG uygulaması gerektiren tampon gömülmesi tüm PEG uygulamalarının \%2,4'ünde görüldü. Tüm komplikasyonların yaş gruplarına göre karşılaştırmasında istatistiksel olarak fark saptanmadı $(\mathrm{p}=0,573)$. Komplikasyon görülme zamanı en erken işlem sonrası 1. gün, en geç ise 3 yll sonra idi. Komplikasyon meydana gelme zamanı açısından yaş gruplarına göre anlamlı farklılık izlenmedi $(\mathrm{p}=0,235)$.

Tüm hastaların takip sürelerine bakıldığında, ortanca \pm çeyrekler arası aralık (IQR) takip süresi 282,5 \pm 741 gün idi. 79 yaş altı grupta takip süresi ortanca \pm IQR $338 \pm 947$ gün iken, 80 yaş ve üzeri grupta $277 \pm 649$ gün idi $(p=0,056)$. Üçüncü ay sağ kalım oranları orta yaş grubunda \%70,9 iken, yaşlı grupta \%65 idi. Birinci yıl sağ kalım oranlarına bakıldığında ise orta yaş grubunda \%53,7 iken, yaşl grupta \%46 idi, buna göre gruplar arasında istatistiksel olarak anlaml farklllı izlenmedi ( $\mathrm{p}=0,110)$ (Şekil 1).

\section{TARTISQMA}

Bu retrospektif çalışmamızda, PEG'in kliniğimizde yıllar içinde daha yaşlı bir hasta popülasyonuna ve en sık SVO endikasyonu ile uygulandığını saptadık. Bu gözleme dayanarak

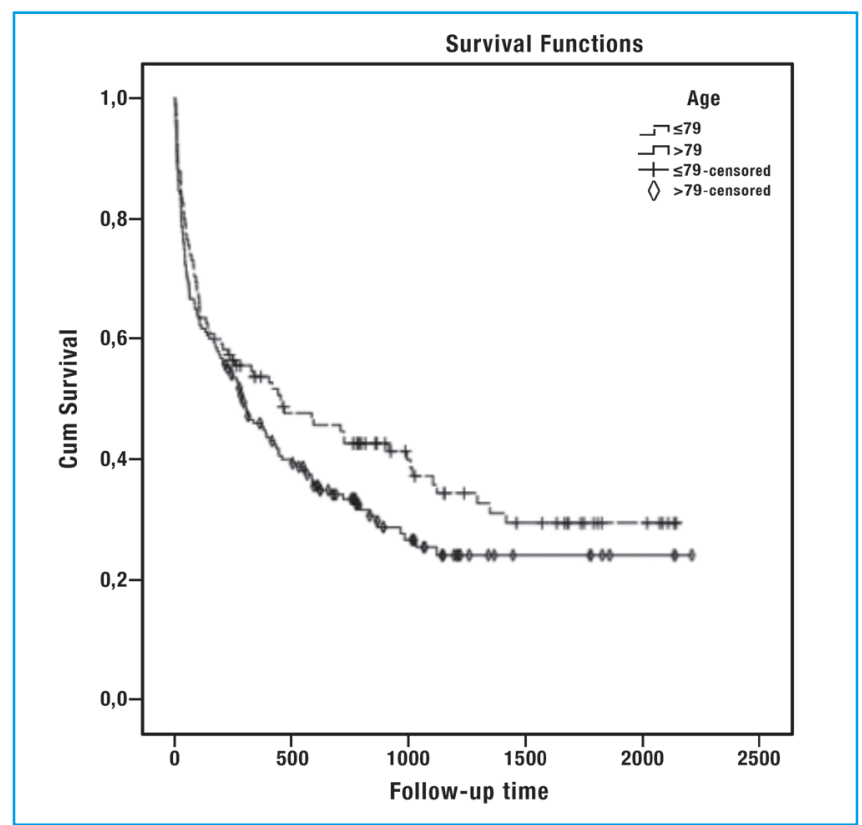

Şekil 1. 79 yaş altı ve 80 yaş üzeri grupta sağ kalım karşılaştırmasında fark saptanmamıștır. hastalarımızı Dünya Sağlık Örgütü yeni sinıflamasına göre 79 yaş ve altı orta yaş hasta grubu, 80 yaş ve üzeri yaşlı hasta grubu olmak üzere değerlendirdik. PEG uygulama endikasyonu açısından her iki yaş grubunda da en sık endikasyon serebrovasküler olay idi. Yeniden PEG uygulaması ile PEG komplikasyonları da yaş gruplarına göre farklılık göstermemekteydi. Ancak PEG sonrası hastanede kalma süresi açısından yaşlı grubun daha uzun süreli izleme ihtiyacı olduğunu saptadık. Üç aylık ve bir yıllık sağ kalım süresi açısından ise yaş grupları arasında anlamlı fark saptanmazken, bu sağ kalım oranlarının literatürde belirtilen sürelere benzer olduğu gözlendi.

Türkiye Istatistik Kurumu verilerine göre ülkemizde 65 yaş üzeri nüfus 2013 yllında $\% 7,7$ iken, nüfus projeksiyonlarına göre 2023 'de \%10,2'e ve 2050 'de \%20,8'e ulaşacağı öngörülmektedir (8). Ülkemizde yaşlı nüfus artış hızı, diğer yaş gruplarına ve toplam nüfus artışına göre 3 kat daha fazladır (8). Merkezimizde son 5 yll içinde PEG uygulanan hastaların ortanca yaşı 79,5 yıldan 86 yıla ulaşmıştır. Yani Türkiye nüfusundaki yaşlanma, küçük bir model olarak kliniğimize de yansımaktadır.

PEG uygulama endikasyonunun literatürde coğrafi bölgelere göre değişebildiği görülmüştür. Almanya'dan yapılan bir çalışmada ortanca yaşı 63 olan 119 hastanın en sık PEG endikasyonu disfajiye yol açan tümörlerdir (9). Oysa 545 hastanın izlendiği bir Japon çalışmasında hastaların ortalama yaşı 77,2 yll olup en slk PEG endikasyonu SVO'dur (10). Bizim çalışmamızda, orta yaş ve yaşlı hasta grupları arasında PEG uygulama endikasyonu açısından en sık nörolojik hastalıklar PEG endikasyonu göstermekteydi. Endikasyon alt gruplarına baktığımızda SVO birinci sırada olup bunu demans, hipoksik ensefalopati ve Parkinson hastallğı takip etmekteydi. Yaş gruplarına göre bakıldığında 80 yaş üzeri grupta SVO ve demans daha fazla iken, hipoksik ensefalopati ve maligniteler 79 yaş ve altı grupta daha fazla idi. Çalışmamızda dikkat çeken diğer bir husus, ylllar içinde SVO'lu hastaların sayısının da artıs göstermesiydi. Bunun sebebi eşlik eden metabolik sendrom X, diabetes mellitus ve ateroskleroz olabilir. Oysa Tayvan'dan yapılan çalışmada 1997-2010 arası takipte PEG endikasyonlarının yıllar içinde malignite yönünde değiştiği görülmüş. Önceleri sıklıkla serebrovasküler hastalık sebebiyle PEG uygulanırken, ilerleyen zamanda özofageal kanser sebebiyle PEG uygulamalarının arttı̆̆ı rapor edilmiş (11). Maligniteler açısından literatürde PEG endikasyonu sıklıkla baş boyun tümörlerinedir $(4,6)$. Literatürde en geniş seri 565 baş-boyun tümörlü hasta ile Burney ve Bryner'a aittir (12). Bizim çalışmamızda PEG gereksinimi en sık metastatik akciğer kanseri olgularında olmuştur. Bu durum Türkiye Halk Sağlığ Kurumu Kanser Daire Başkanlığı 2014 verilerine dayandırılacak olursa, ülkemizde halen akciğer kanseri insidansı en yüksektir (13). Bundan ötürü daha fazla akciğer karsinomlu olgu 
ile karşılaşılması ve bu hastalarda lokal ilerleme, metastaz veya radyoterapi komplikasyonu daha fazla PEG ihtiyacını doğurmaktadır. Ayrıca 2017'de yayınlanan bir makalede metastatik kanserler içinde mekanik ventilasyon, diyaliz ve PEG gibi yoğun bakım tedavisi gerektiren en sık kanserin akciğer kanseri olduğu saptanmıştır (14).

PEG uygulamasını takiben hastaların hastanede kalma süresi, yaşlı hasta grubunda daha uzun idi. Hastaların hastanede yatmalarını gerektiren PEG işlemi veya herhangi PEG komplikasyonu değil, eşlik eden hastalıkların yönetimi idi. Çalışmamızda orta yaş ve yaşlı grup arasında eşlik eden hastalık sıklığı açısından fark saptanmasa da ek hastalık şiddeti, yönetimi, medikasyonu, yoğun bakımda bulunma hali ve sosyal koşullar PEG sonrası hastanede kalma süresini etkileyecek faktörler olabileceği düşünüldü. Fakat bu noktada çalışmamızın kısıtlı tarafı hastaların laboratuvar verilerinin, klinik veya laboratuvar skorlamalarının eksik olmasıdır. Hastaların sağ kalımını etkilemeyen ama kısa vadede hastanede kalma sürelerini etkileyen hususlar retrospektif çalışma handikapları sebebiyle detaylandırılamamıştır.

PEG uygulamasına bağlı lokal komplikasyonlar literatürde \%5-25 olarak bildirilmektedir $(5,6)$. Türkiye'den Gündoğan ve arkadaşlarının yaptı̆̆ retrospektif analizde işlem sonrası erken dönemde en slk kateter yerinden kanama olup 128 hastanın \%4'ünde görülmüş (15). Kore'den yapılan bir çalışmada ise 245 hastanın 27'sinde (\%11) minör komplikasyon görülmüş olup 22'sinde özofagusda minör kanama, 4'ünde peristomal minimal enfeksiyon saptanmış (16). Çalışmamızda ise en sık komplikasyon peristomal sızıntı veya kanamadır. Yaş gruplarına göre karşılaştırma yapıldığında istatistiksel olarak anlamlı farklılık saptanmadı. Hastalarımızın hiçbirinde PEG işlemine bağlı mortalite görülmedi. Komplikasyonlar çeşitli yayınlarda ileri yaş, erkek cinsiyet, hipoalbuminemi, C-reaktif protein (CRP) yüksekliği ve düşük vücut kitle indeksi ile ilişkilendirilmektedir (15-17). PEG işlemi teknik olarak zor değildir, ancak PEG uygulaması sonrası hastanın takibi, minör veya majör komplikasyonların izlemi için multidisipliner yaklaşım gerekmektedir (17). Merkezimizde PEG talep eden kliniklerin, PEG zamanlaması açısından hastanın işleme engel olabilecek medikal özgeçmiş özelliklerini gözden geçirip, enfeksiyon tablosunun olmadığı, antikoagülan

\section{KAYNAKLAR}

1. http://www.un.org/en/development/desa/population/publications/pdf/ ageing/WPA2015_Report.pdf. United Nations, Department of Economic and Social Affairs, Population Division (2015). World Population Ageing 2015 (ST/ESA/SER.A/390))

2. Muscedere J, Andrew MK, Bagshaw SM, et al. Screening for friality in Canada's health care system: A time for action. Can J Aging 2016;35:28197.

3. Löser C, Aschl G, Hébuterne X, et al. The European Society for Clinical Nutrition and Metabolism (ESPEN) guidelines on enteral nutrition-percutaneous endoscopic gastrostomy. Clin Nutr 2005;24:848-61. veya antiagregan ilaç kullanımının işlem öncesi uygun biçimde düzenlendiği bir zamanı seçmeleri önemli bir kolaylık sağlamaktadır. Endoskopi ünitemizde çalışanların işlem öncesi hazırlık ve işlem sürecindeki uyumu, uygulamanın hızlı ve en az hata ile olmasını temin etmektedir. Ayrıca özellikle PEG işlemi sonrası hem kateter bakımı hem de PEG'den beslenme takibi açısından tecrübeli bakımevi çalışanlarının olması bu sonuca katkıda bulunmaktadır.

PEG uygulaması yapılan hastalarımızın üçüncü ay sağ kalım oranları orta yaş grubunda $\% 70,9$, yaşlı grupta $\% 65$ idi. Birinci yıl sağ kalım oranlarına bakıldığında ise orta yaş grubunda $\% 53,7$ iken, yaşlı grupta \%46 idi, buna göre gruplar arasında anlamlı farklılık izlenmedi $(\mathrm{p}=0,110)$. Nörolojik sebepler ile PEG uygulanmış altmış beş yaş üzeri 931 hastanın katıldığı çok merkezli Japon çalışmasında, bir yıllık sağ kalım \%66 idi (18). Bu çalışmada PEG'li hastaların yarıdan fazlasının 2 ylldan uzun yaşadığı gösterilmiştir (18). Kore'den yapılan bir çalışmada ise geriatrik hasta grubunda PEG uygulaması, genç yaş grubu ile karşılaştırıldığında, güvenli bulunmuş, yaşın işlem ile ilişkili komplikasyon veya mortaliteyi etkilemediği rapor edilmiştir (19). Wu ve arkadaşlarının Çin'de yaptıkları incelemede, PEG uygulanan ortalama yaşları 63,3ะ9,4 olan SVO'lu hastaların ortanca sağ kalımı 17,6 ay iken, PEG uygulanmayanlarınki 8,2 ay olarak rapor edilmiştir (20). Kara ve arkadaşlarının çalışmasında ise nörolojik hastalıklar sebebiyle PEG uygulanan ortanca yaşı 77 yl olan 500 hastanın üç aylık mortalite oranı \%28'dir (21). Mortaliteyi etkileyen faktörlerin SVO varlığı ve nötrofil yüzdesindeki yükseklik, sağ kalımı etkileyen faktörlerin ise hiperlipidemi ve proflaktik antibiyotik kullanımı olduğu saptanmıştır (21). Çalışmamızda sağ kalım süresi literatür ile karşılaştırıldığında benzer olarak bulunmuştur. Üstelik PEG uyguladığımız hastalarımızın ortanca yaşı 82 olup bu önceki çalışmalara göre daha ileri yaştır. Böylelikle çalışmamızda PEG’in, yaşlı hasta grubunda güvenli bir yöntem olduğunu ifade edebiliriz. Ayrıca PEG uygulamasının da tek başına yaşın sağ kalımı etkilemediğini vurgulamak isteriz. 80 yaş ve üzeri hasta grubunda yaşam kalitesini arttırmak, malnütrisyonu engellemek, tekrarlayan enfeksiyonlar ile hastaneye yatışs sıklı̆ını azaltmak için PEG, sağkalımı olumsuz etkilemeyen, kolay erişilebilir ve güvenli bir yöntemdir.
4. Itkin M, DeLegge MH, Fang JC, et al; Society of Interventional Radiology; American Gastroenterological Association Institute; Canadian Interventional Radiological Association; Cardiovascular and Interventional Radiological Society of Europe. Multidisciplinary practical guidelines for gastrointestinal access for enteral nutrition and decompression from the Society of Interventional Radiology and American Gastroenterological Association (AGA) Institute, with endorsement by Canadian Interventional Radiological Association (CIRA) and Cardiovascular and Interventional Radiological Society of Europe (CIRSE). Gastroenterology 2011;141:742-65. 
5. Hucl T, Spicak J. Complications of percutaneous endoscopic gastrostomy. Best Prac Res Clin Gastroent 2016;30:769-81.

6. Rahnemai-Azar AA, Rahnemai-Azar AA, Naghshizadian R, et al. Percutaneous endoscopic gastrostomy: Indications, technique, complications and management. World J Gastroenterol 2014;20: 739-51.

7. Gauderer MW, Ponsky JL, Izant RJ. Gastrostomy without laparotomy: A percutaneous endoscopic technique. J Pediatric Surg 1980;15:872-5.

8. www.tuik.gov.tr. Türkiye Istatistik Kurumu, Temel Istatistikleri, Nüfus ve Demografi, Nüfus Projeksiyonları.

9. Schieneider AS, Schettler A, Markowski A, et al. Complication and mortality rate after percutaneous endoscopic gastrostomy are low and indication-dependent. Scand J Gastroenterol 2014;49:891-8.

10. Kasuno C, Yamada N, Kikuchi K, et al. Current status of percutaneous endoscopic gastrostomy in general hospital in Japan: a cross-sectional study. J Rural Med 2016;11:7-10.

11. Chang WK, Lin KT, Tsai CL, et al. Trends regarding percutaneous endoscopic gastrostomy: A nationwide population-based study from 1997 to 2010. Medicine (Baltimore)2016;95(24):e3910.

12. Burney RE, Bryner BS. Safety and long-trem outcomes of percutaneous endoscopic gastrostomy in patients with head and neck cancer. Surg Endosc 2015;29:3685-9.

13. Türkiye Halk Sağlığı Kurumu Kanser Daire Başkanlığı, 2014 Yılı Türkiye Kanser Istatistikleri www.kanser.gov.tr
14. Loh KP, Kansagra A, Shieh MS, et al. Predictors of the use of spesific critical care therapies in patients with metastatic cancer. J Natl Compr Canc Netw 2017;15:22-30.

15. Gündoğan K, Yurci A, Coşkun R, et al. Outcomes of percutaneous endoscopic gastrostomy in hospitalized patients at a tertiary care center in Turkey. Eur J Clin Nutr 2014;68:437-40.

16. Lee SP, Lee KN, Lee OY, et al. Risk factors for complications of percutaneous endoscopic gastrostomy. Dig Dis Sci 2014;59:117-25.

17. Lee C, Im JP, Kim JW, et al; Small Intestine Research Group of the Korean Association for the Study of Intestinal Disease (KASID). Risk factors for complications and mortality of percutaneous endoscopic gastrostomy: a multicenter, retrospective study. Surg Endosc 2013;27:380615.

18. Suzuki Y, Tamez S, Murakami A, et al. Survival of geriatrics patients after percutaneous endoscopic gastrostomy in Japan. World J Gastroenterol 2010;16:5084-91.

19. Oh DJ, Kim B, Lee JK, et al. Can percutaneous endoscopic gastrostomy be carried out safely in the elderly? Geriatr Gerontol Int 2016;16:481-5.

20. Wu K, Chen Y, Yan C, et al. Effects of percutaneous endoscopic gastrostomy on survival of patients in a persistent vegetative state after stroke. J Clin Nurs 2016;26:3232-8.

21. Kara Ö, Kızılarslanoğlu MC, Canbaz B, et al. Survival after percutaneous endoscopic gastrostomy in older adults with neurologic disorders. Nutr Clin Pract 2016;31:799-804. 